\begin{tabular}{|c|l|}
\hline Title & $\begin{array}{l}\text { High-temperature properties of extruded titanium composites fabricated from carbon nanotubes coated titanium powder } \\
\text { by spark plasma sintering and hot extrusion }\end{array}$ \\
\hline Author(s) & Kondoh, Katsuy oshi; Threrujirapapong, Thotsaphon; U meda, Junko; Fugetsu, Bunshi \\
\hline Citation & $\begin{array}{l}\text { Composites Science and Technology, 72(11), 1291-1297 } \\
\text { https://doi.org/10.1016/.compscitech.2012.05.002 }\end{array}$ \\
\hline Issue Date & 2012-06-28 \\
\hline Doc URL & http://hdl.handle.net/2115/49691 \\
\hline Type & article (author version) \\
\hline File Information & CST 72-11_1291-1297.pdf \\
\hline
\end{tabular}

Instructions for use 


\section{High-temperature properties of extruded titanium composites fabricated from carbon nanotubes coated titanium powder by spark plasma sintering and hot extrusion}

Katsuyoshi Kondoh $^{1)^{*}}$, Thotsaphon Threrujirapapong ${ }^{2)}$, Junko Umeda ${ }^{1)}$, Bunshi Fugetsu ${ }^{3)}$

1) Joining and Welding Research Institute, Osaka University, Osaka, Japan.

${ }^{2)}$ Industrial Engineering Department, Naresuan University, Phitsanulok, Thailand.

${ }^{3)}$ Graduate School of Environmental Science, Hokkaido University, Hokkaido, Japan

\section{Abstract}

Pure titanium matrix composite reinforced with carbon nanotubes (CNTs) was prepared by spark plasma sintering and hot extrusion via powder metallurgy process. Titanium (Ti) powders were coated with CNTs via a wet process using a zwitterionic surfactant solution containing 1.0, 2.0 and 3.0wt.\% of CNTs. In-situ TiC formation via reaction of CNTs with titanium occurred during sintering, and $\mathrm{TiC}$ particles were uniformly dispersed in the matrix. As-extruded Ti/TiCs composite rods were annealed at $473 \mathrm{~K}$ for $3.6 \mathrm{ks}$ to reduce the residual stress during processing. After annealing process, the tensile properties of the composites were evaluated at room temperature, 473, 573 and $673 \mathrm{~K}$, respectively. Hardness test was also performed at room temperature up to $573 \mathrm{~K}$ with a step of $50 \mathrm{~K}$. The mechanical properties of extruded Ti/CNTs composites at elevated temperature were remarkably improved by adding a small amount of CNTs, compared to extruded Ti matrix. These were due to the $\mathrm{TiC}$ dispersoids originated from CNTs effectively stabilized the microstructure of extruded Ti composites by their pinning effect. Moreover, the coarsening and growth of Ti grain never occurred even though they were annealed at $573,673 \mathrm{~K}$ for $36 \mathrm{ks}$ and $673 \mathrm{~K}$ for $360 \mathrm{ks}$, respectively.

\section{Keywords}

A. Metal-matrix composites, A. Carbon nanotubes, E. Powder processing 


\section{Introduction}

Since the official report of carbon nanotubes (CNTs) by Iijima in 1991 [1], they have been expected to be a promising reinforcement in composite materials processing because they remarkably show superior mechanical properties such as high Young's modulus of about 1TPa and tensile strength of about 20 GPa [2-4]. Recently, CNTs have been widely used as reinforcing materials for metal matrix composites (MMCs). The previous studies indicated the remarkable characteristics of MMCs reinforced with CNTs, such as aluminium [5-7], magnesium [8-10], copper [11-12] and titanium [13-16]. Ti and its alloys are also interested as competitive matrix materials because they exhibit high specific strength which is an important factor for weight reduction of the airplane and automotive applications from the viewpoint of energy consumption. The previous work [14] has demonstrated a successful improvement of tensile properties at room temperature of the commercially pure $\mathrm{Ti}$ reinforced with CNTs via wet processing in powder metallurgy route. However, the improvement of mechanical properties of commercially pure $\mathrm{Ti}$ at elevated temperature is also important because some applications need to use or exposure to high temperature such as exhaust system of airplanes, automotives and power plants [17-18]. Xue et al. [16] have reported good compressive properties of Ti/CNTs composite materials at $873 \mathrm{~K}$. However, the tensile properties and hardness of those Ti/CNTs composite materials at elevated temperature have not been studied. In the present study, the commercially pure titanium matrix reinforced with $\mathrm{TiC}$ particles and CNTs were prepared by wet processing, and consolidated by spark plasma sintering and hot extrusion as wrought composites. The effect of dispersoids in the Ti matrix on microstructures of the composites at elevated temperature was investigated. Finally, the tensile properties and hardness of extruded Ti/TiCs composites were evaluated at elevated temperature 


\section{Experimental}

The pure Ti powders grade 2 with the purity of $95 \%$ were used as starting materials. The mean particles size of pure $\mathrm{Ti}$ powders is $30 \mu \mathrm{m}$. The chemical compositions of the pure Ti powders are listed in Table 1. Carbon nanotubes (CNTs) made by Bayer MaterialScience with an average diameter of $20 \mathrm{~nm}$ and $1 \sim 10 \mu \mathrm{m}$ in length were used as the reinforcing materials in the present study. Typical linear zwitterionic surfactant solutions containing the CNTs concentration of 1.0, 2.0 and 3.0wt.\% were prepared. The pure Ti powders were coated by the different concentration of the aqueous CNT/zwitterionic solutions and subsequently dried in an oven at $373 \mathrm{~K}$ for $10.8 \mathrm{ks}$. The solid zwitterionic substances were solidified as thin film solids and existed on the Ti surface during drying process. Those thin film solids needed to be eliminated before consolidation because they were changed to gases at temperature of above $773 \mathrm{~K}$ [14], resulting in pore defects in the consolidated bulk materials. The coated Ti powders were heated again in a horizontal tube furnace at $873 \mathrm{~K}$ for $3.6 \mathrm{ks}$ under a protective $\mathrm{Ar}$ gas. The image of CNT coated Ti particle is shown in Fig. 1. The Ti powders coated with CNTs were consolidated by SPS (Syntech Co. SPS-103S) process at $1073 \mathrm{~K}$ for $1.8 \mathrm{ks}$ under vacuum $(<4 \mathrm{~Pa})$. The applied pressure during SPS process was constantly kept at 30 MPa. The sintered Ti billet was then heated to $1273 \mathrm{~K}$ for $180 \mathrm{~s}$ under an Ar atmosphere, and immediately underwent to a hot extrusion process. The extrusion ratio, speed, mold and die temperature were $37,3.0 \mathrm{~mm} / \mathrm{s}$ and $673 \mathrm{~K}$, respectively.

To reduce the residue stress during processing, the extruded Ti composites were annealed at the low temperature of $473 \mathrm{~K}$ for $360 \mathrm{ks}$. The microstructure and phase characterization of extruded $\mathrm{Ti}$ composites were investigated by optical microscopy, a scanning electron microscope (SEM, JEOL: JSM-6500F) and X-ray diffractometer (XRD, 
Shimadzu: XRD-6100). The Cohen's method of least square analysis [19] was used to estimate the change of lattice parameter, a and c axes, of the extruded Ti composite materials. Moreover, the amount of in-situ formed TiC dispersoids was also estimated by comparing the peak intensity ratio of $\mathrm{TiC} / \mathrm{Ti}$ in the $\mathrm{XRD}$ results with a $\mathrm{TiC}$ calibration curve. The internal standard technique [19] was used to prepare the TiC calibration curve by plotting the ratio of maximum intensity of $\mathrm{TiC} / \mathrm{Ti}$ peaks in XRD result against the known concentration of TiC particles in the Ti powders. The extruded Ti composites after the annealing process were machined into tensile specimen bars of $3.0 \mathrm{~mm}$ in diameter and $20 \mathrm{~mm}$ in gauge length. The tensile properties at room temperature were evaluated using universal test machine (Autograph AG-X 50kN, Shimadzu) under a strain rate of 5 $\times 10^{-4} \mathrm{~s}^{-1}$ Hardness at room temperature was also measured by a micro-Vickers hardness tester (Shimadzu: HMV-2T). In addition, the tensile properties at elevated temperature were evaluated using a horizontal high temperature tensile testing machine (Yonekura: CATY-T3H-KD 5KN) at 473, 573 and $673 \mathrm{~K}$, respectively, under the same strain rate as mentioned above. Hardness at elevated temperatures was also evaluated by the same hardness tester which was attached to homemade heating equipment. The holding time at the given temperature before measurement of both tensile and hardness test was $300 \mathrm{~s}$.

\section{Results and discussion}

Fig. 2 shows the optical microstructure images of extruded pure Ti material before and after annealing at $473 \mathrm{~K}$ for $360 \mathrm{ks}$. The grain size measurements before and after annealing of those extruded pure Ti material with no CNT indicate the average value of 11.7 and $44.7 \mu \mathrm{m}$, respectively. A large increase in grain size of extruded pure Ti material is due to the recovery process and coarsening of $\mathrm{Ti}$ grain occurred during a long time annealing [20]. On the other hand, the microstructures of extruded pure Ti/TiCs 
composites both before and after annealing process reveal the unchanged grain size as shown by the representative microstructures of the extruded pure $\mathrm{Ti} / \mathrm{TiC}$ by using 1.0wt.\% CNTs/zwitterionic solution in Fig.2(c) and (d). The grain size measurement results of all composite materials almost show the same size in the range of 7.4 to $8.6 \mu \mathrm{m}$ as summarized in Table 2 . The very small changes in grain size are due to the pinning effect of TiC dispersiods which retard the Ti grain coarsening during annealing process as mentioned next.

XRD patterns of the extruded Ti composites after annealing are shown in Fig. 3. The XRD results have confirmed only in-situ formed $\mathrm{TiC}$ dispersoid, not $\mathrm{TiO}_{2}$ and $\mathrm{TiN}$, existing in the Ti matrix. That means no oxidation and nitridation were detected by XRD inside the extruded $\mathrm{Ti} / \mathrm{TiCs}$ composites during SPS, hot extrusion and annealing process. A quantitative estimation of the in-situ formed $\mathrm{TiC}$ dispersoid content reveals the $\mathrm{TiC}$ contents of $0.61,1.58$ and $2.55 \mathrm{wt} . \%$ for the composite by using 1.0, 2.0 and $3.0 \mathrm{wt} . \%$ CNTs/zwitterionic solution, respectively. Furthermore, the lattice expansion of Ti matrix is also calculated to investigate the possibility of carbon atom dissolved into the Ti matrix. The calculation of precise lattice parameters, a and c, of Ti using the Cohen's least squares method [19] indicated that the carbon atom originating from CNTs and/or in-situ formed $\mathrm{TiC}$ dispersoids can be dissolved into $\mathrm{Ti}$ matrix, resulting in expansion of $\mathrm{Ti}$ lattice parameters. The amount of dissolved carbon atom can be further estimated by comparing the Ti lattice expansion results with the master plot which was reported by $\mathrm{H}$. Conrad [21]. The calculation of $\mathrm{Ti}$ lattice parameters and the estimation results of the $\mathrm{TiC}$ dispersoid amount, dissolved carbon atom and the carbon content analysis are summarized in Table 3. It should be note that the maximum equilibrium solubility of carbon in $\alpha$-Ti from is 0.4 wt.\% [22] 
The tensile test results at room temperature and elevated temperature of extruded Ti/TiCs composites after annealing at $473 \mathrm{~K}$ for $3.6 \mathrm{ks}$ are shown in Fig. 4. The improvement of mechanical properties, in particular yield stress, of the composites at room temperature can be considered that due to the effect of grain size, solid solution of carbon and TiC second phase including the remained CNTs $[10,14]$. The strengthening mechanism due to grain size effect was estimated by Hall-Petch relationship [23-24] using the material constants in Ref. [24]. The values of $\sigma_{0}$ and $k$ constants are $172.5 \mathrm{MPa}$ and $18 \mathrm{MPa} \sqrt{ } \mathrm{mm}$, respectively, at room temperature. Unfortunately, due to the lack of information of $k$ constants for elevated temperatures, the estimation steps were started by comparing the yield stress in this study and the previous results [25] to obtain $k$ constants, and then the rest constant will be obtained. The estimated values of $\sigma_{0}$ constants are 1.9, 2.7 and 2.0 $\mathrm{MPa}$, and $k$ constants are $17.5,8.4$ and $9.3 \mathrm{MPa} \sqrt{\mathrm{mm}}$ for the temperatures of 473,573 and $673 \mathrm{~K}$, respectively. It should be noted that the $k$ constant of $17.5 \mathrm{MPa} \vee \mathrm{mm}$ at 473 is close to $18 \mathrm{MPa} \sqrt{ } \mathrm{mm}[24]$ at room temperature. This can be implied that the strain hardening effect due to grain size is strongly dominated the yield stress of extruded pure Ti during tensile testing until $473 \mathrm{~K}$. After $473 \mathrm{~K}$, the $k$ constant is obviously decreased because of the increasing effect of recovery process in accordance with the previous reports [25]. The effect of carbon solid solution can be estimated by comparing the amount of dissolved carbon atom in this study with a plot of the dependence of carbon solute atom on the incremental yield stress in the previous study [21]. The strengthening mechanisms of each effect are summarized in Table 4. As the results of strengthening estimation, the increase of yield stress of the extruded Ti/TiCs composites are mainly due to the dispersion strengthening mechanism of the second phases (TiC particles and the remained CNTs) and the grain size effect, while the carbon solid solution shows a very small effect on the increase of yield stress. The effects of oxygen and nitrogen $[21,26]$ 
are also taken into account in the same effect as well as carbon. However, the previous study [27] suggested that the oxygen and nitrogen contents in the composite, which was consolidated using the same materials and conditions with this study, are very small and close to the starting content in the raw powders. Therefore, the effect of oxygen and nitrogen may not significantly increase the mechanical properties of extruded $\mathrm{Ti}$ composites at room temperature and elevated temperature, compared to the effect of insitu formed TiC dispersoids in this study. The remained CNTs have been detected in the fractured surfaces of all samples after annealing process and tensile testing at elevated temperatures as shown by the representative sample of the extruded pure Ti/TiCs by using 1.0wt.\% CNTs/zwitterionic solution tested at $673 \mathrm{~K}$ in Fig. 5. Unfortunately, the exact strengthening mechanism by the remained CNTs in the Ti composites at room and elevated temperatures is still unclear because the exact amount of CNTs transformed to TiC is unknown. However, the remained CNTs are expected to improve the mechanical properties which are consistent with the previous report [10, 13-15].

The microstructures of Ti composite materials after annealing are shown in Fig. 6(a)-(c). The microstructures show the presence of fine $\mathrm{TiC}$ particles and $\mathrm{Ti}$ matrix. $\mathrm{TiC}$ particles were possibly synthesized via reaction between Ti powder and CNTs during SPS process at $1073 \mathrm{~K}$ for $1.8 \mathrm{ks}$. This is because from a thermodynamic point of view, $\Delta \mathrm{G}^{\mathrm{o}}$ of $\mathrm{TiC}$ formation at $1073 \mathrm{~K}$ is $-171.3 \mathrm{~kJ} / \mathrm{mol}$. [28], and the above reaction spontaneously progresses during the sintering process. TiC particles are distributed throughout the $\mathrm{Ti}$ matrix, which can account for the high dispersion of CNTs on the Ti powder surface during coating step. However, there are some large TiC particles existing in the microstructure. This is due to the clusters of individual CNTs at the facet or curve of Ti powder in Fig. 1 are recombined and formed into a large TiC particle which is an inevitable phenomenon in the wet process. The in-situ formed $\mathrm{TiC}$ dispersoids both 
before and after annealing almost show the same mean size of $2.0 \mu \mathrm{m}$ as summarized in Table 2. The high distribution of $\mathrm{TiC}$ dispersoids effectively restrains the deformation of Ti grains which in turn maintain the stability of $\mathrm{Ti}$ grain during elevated temperature tensile testing. Moreover, the increase of TiC dispersoids is also effective to improve the retardation of Ti grain sliding. The microstructure observation of the tensile test sample of extruded Ti/TiCs composite by using 3.0wt.\%CNTs/zwitterionic solution at the necking area confirms the retardation of grain boundary sliding by TiC particle as shown in Fig. 6(d)

The higher temperature causes the lower YS and TS of all tested samples. That can be explained by the diffusion-controlled creep phenomenon [29-31]. At elevated temperature, $\mathrm{Ti}$ atoms at grain boundaries which are parallel to the tensile stress axis can be diffused into another side of grain boundaries which are perpendicular to the tensile stress axis. It causes a plastic elongation of $\mathrm{Ti}$ grains along the tensile axis and decrease of the cross sectional area of the test specimen quickly. However, in the case of extruded Ti/TiCs composites containing a small mount of original CNTs, the YS and TS are higher than those of extruded pure $\mathrm{Ti}$ material. For example, the composite by using 3.0wt.\%CNTs/zwitterionic solution shows YS and TS values higher than those of extruded pure Ti material of $40.4 \%$ and $109.1 \%$, respectively, at the tested temperature of $673 \mathrm{~K}$. This is because the in-situ formed TiC dispersoids inhibit the coarsening of $\mathrm{Ti}$ grain by their pining, as shown in the grain size measurement results at each testing temperature in Fig. 6(d) and Table 2, which in turn impede the motion of Ti atoms to another side of the grain boundaries. According to the quantitative analysis of $\mathrm{TiC}$ dispersoids from XRD results, the increase of TiC dispersoid content in the extruded $\mathrm{Ti}$ composites can effectively improve the retardation of $\mathrm{Ti}$ grain coarsening which in turn increases the stability of strength of the composites by the pinning and dispersion 
strengthening mechanisms during elevated temperature tensile testing. Elongation of all extruded $\mathrm{Ti} / \mathrm{TiCs}$ shows the lower percentage than that of extruded pure Ti material in every tested temperature. This is due to the fact that in-situ TiC dispersoid is a hard intermetallic phase which is never plastically deformed at elevated temperature of $673 \mathrm{~K}$. As a result, the extruded Ti composite using 3.0wt.\%CNTs/zwitterionic solution revealed the lowest elongation in all of the extruded $\mathrm{Ti}$ composite materials. The dependence of micro hardness on testing temperatures of the composites is shown in Fig. 7. The results indicate the decreasing tendency upon exposure at elevated temperature, and can be explained by the softening mechanism [32]. Dislocation and other defects of the composites are annihilated by the recovery process, resulting in decrease of the hardness of material. The rate of recovery is strongly dependent on temperature. Therefore, the micro hardness measurements of all samples at $573 \mathrm{~K}$ yield the lowest hardness value, compared to the other temperatures. The increase of $\mathrm{TiC}$ particles dispersed in the $\mathrm{Ti}$ matrix also helps to increase the resistance to the applied pressure during hardness test. Consequently, the extruded Ti composite by using 3.0 wt.\% CNTs/zwitterionic solution can maintain higher hardness than those of 1.0 and $2.0 \mathrm{wt} . \% \mathrm{CNTs} / \mathrm{zwitterionic}$ samples, respectively.

In order to confirm the pinning effect of $\mathrm{TiC}$ dispersoids, the $\mathrm{Ti}$ composites were annealed at the higher temperatures of 573,673 for $36 \mathrm{ks}$ and $673 \mathrm{~K}$ for $360 \mathrm{ks}$. The evolution of microstructures is shown in Fig. 8. The microstructure of the extruded pure Ti material shows the increase of grain size when the annealing temperature is increased from 573 to $673 \mathrm{~K}$, as shown in Fig. 8 (a) and (b). On the other hand, the grain size measurement results of the composite materials show very small increase of Ti grain size as shown in successive Fig. 8 (d)-(1). The small increase of Ti grain size can confirm the pinning effect of $\mathrm{TiC}$ dispersoids which help to suppress $\mathrm{Ti}$ grain growth during the 
annealing process. The annealing at $673 \mathrm{~K}$ for $360 \mathrm{ks}$ also shows very small changes in $\mathrm{Ti}$ grain size in the case of extruded $\mathrm{Ti} / \mathrm{TiCs}$ composites. In contrast, the extruded pure $\mathrm{Ti}$ material shows the decrease in grain size, as shown in Fig. 8 (c), because the recrystallization process occurs during long time annealing process according to the previous reports [20]. The presence of $\mathrm{TiC}$ dispersoids also retards the recrystallization of new grains when the long time annealing because the TiC pinning pressure is higher than driving pressure for recrystallization nucleation of new grain. Therefore, the recrystallization may never occurs in the case of the composites which are annealed at 673 for 360 ks as shown in Fig. 8 (f), (i) and (1), respectively. High magnification images of extruded $\mathrm{Ti} / \mathrm{TiCs}$ composites have also confirmed the unchanged $\mathrm{Ti}$ grain size after annealing at $673 \mathrm{~K}$ for $360 \mathrm{ks}$ as shown in Fig. 9. The microstructural stability of the composites after annealing at different temperatures and times can be used to confirm the pinning effect due to $\mathrm{TiC}$ dispersoids which help to maintain the Ti grain size invariably during tensile testing at elevated temperatures.

\section{Conclusions}

1) The annealing process at $473 \mathrm{~K}$ for $360 \mathrm{ks}$ significantly affected to the increase of grain size of extruded pure Ti material with no CNT.

2) the grain size of extruded $\mathrm{Ti} / \mathrm{TiCs}$ composites never affected because the pinning effect of $\mathrm{TiC}$ dispersoids retarded the grain coarsening and stabilized the primary Ti grain size.

3) Mechanical properties at the elevated temperature of the composite materials indicated the decreasing tendency of tensile strength, yield strength and hardness.

4) The presence of $\mathrm{TiC}$ dispersoids in the $\mathrm{Ti}$ matrix effectively sustained the recovery process, resulting in maintaining stability of strength and hardness of the Ti composites during the elevated temperature. 


\section{References}

1. S. Iijima, "Helical Microtubules of Graphitic Carbon", Nature, vol. 354 (1991) 56-58.

2. J.-P. Salvetat, J.-M. Bonard, N.H. Thomson, A. J. Kulik, L. Forró, W. Benoit, L. Zuppiroli, "Mechanical Properties of Carbon Nanotubes", Applied Physics A, 69 (1999) 255-260.

3. R. S. Ruoff and D. C. Lorents, "Mechanical and Thermal Properties of Carbon Nanotubes", Carbon, vol. 33, 7 (1995) 925-930.

4. S. R. Bakshi, D. Lahiri and A. Agarwal, "Carbon Nanotube Reinforced Metal Matrix Composites - A Review”, International Materials Reviews, vol. 55, 1 (2010) 41-64.

5. R. George, K. T. Kashyap, R. Rahul and S. Yamdagni, "Strengthening in Carbon Nanotube/Aluminium (CNT/Al) Composites", Scripta Materialia, 53 (2005) 1159-1163.

6. A. M. K. Esawi and M. A. El Borady, "Carbon Nanotube-Reinforced Aluminium Strips", Composites Science and Technology, 68 (2008) 486-492.

7. L. Wang, H. Choi, J. M. Myoung and W. Lee, "Mechanical Alloying of MultiWalled Carbon Nanotubes and Aluminium Powders for The Preparation of Carbon/Metal Composites", Carbon, vol. 47, 15 (2009) 3427-3433.

8. C. S. Goh, J. Wei, L. C. Lee and M. Gupta, "Simultaneous Enhancement in Strength and Ductility by Reinforcing Magnesium with Carbon Nanotubes", Materials Science and Engineering A, 423 (2006) 153-156.

9. C. S. Goh, J. Wei, L. C. Lee and M. Gupta, "Ductility Improvement and Fatigue Studies in Mg-CNT Nanocomposites", Composites Science and Technology, 68 (2008) 1432-1439.

10. K. Kondoh, H. Fukuda, J. Umeda, H. Imai, B. Fugetsu and M. Endo, "Microstructural and Mechanical Analysis of Carbon Nanotube Reinforced Magnesium Alloy Powder Composites", Materials Science and Engineering A, 527 (2010) 4103-4108.

11. P. Quang, Y. G. Jeong, S. C. Yoon, S. H. Hong and H. S. Kim, "Consolidation of 1 vol.\% Carbon Nanotube Reinforced Metal Matrix Nanocomposites via Equal 
Channel Angular Pressing", Journal of Materials Processing Technology, 187188 (2007) 318-320.

12. W. M. Daoush, B. K. Lim, C. B. Mo, D. H. Nam and S. H. Hong, "Electrical and Mechanical Properties of Carbon Nanotube Reinforced Copper Nanocomposites Fabricated by Electroless Deposition Process", Materials Science and Engineering A, 513-514 (2009) 247-253.

13. K. Kondoh, T. Threrujirapapong, H. Imai, J. Umeda and B. Fugetsu, "CNTs/TiC Reinforced Titanium Matrix Nanocomposites via Powder Metallurgy and Its Microstructural and Mechanical properties”, Journal of Nanomaterials, vol. 2008 (2008) Article ID127538, 4 pages, doi:10.1155/2008/127538

14. K. Kondoh, T. Threrujirapapong, H. Imai, J. Umeda and B. Fugetsu, "Characteristics of Powder Metallurgy Pure Titanium Matrix Composite Reinforced with Multi-Wall Carbon Nanotubes", Composites Science and Technology, 69 (2009) 1077-1081.

15. T. Threrujirapapong, K. Kondoh, H. Imai, J. Umeda and B. Fugetsu, "Hot Extrusion of Pure Titanium Reinforced with Carbon Nanotubes", Steel Research International, vol. 81, 9 (2010) 1320-1323.

16. F. Xue, S. Jiehe, F. Yan and C. Wei, "Preparation and Elevated temperature Compressive Properties of Multi-Walled Carbon Nanotube Reinforced Ti Composites", Materials Science and Engineering A, 527 (2010) 1586-1589.

17. C. Leyens and M. Peters, Titanium and Titanium alloys, Wiley-VCH, Germany (2003).

18. G. Lütjering and J.C. Williams, Titanium, $2^{\text {nd }}$ ed., Springer-Verlag, Germany (2007).

19. B. D. Cullity and S.R Stock, Elements of X-Ray Diffraction, $3^{\text {rd }}$ ed., Prentice Hall, USA, (2001).

20. F. J. Humphreys and M. Hatherly, Recrystallization and Related Annealing Phenomena, $2^{\text {nd }}$ ed., Elsevier Ltd., Netherlands (2004)

21. H. Conrad, "Effect of Interstitial Solutes on The Strength and Ductility of Titanium”, Progress in Materials Science, 26 (1981) 123-403

22. ASM Handbook vol. 3, Alloy Phase Diagrams, ASM International.

23. R. M. Aikin, Jr., "The Mechanical Properties of In-Situ Composites”, JOM, 49, 8 (1997) 35-39. 
24. Y. Kobayashi, Y. Tanaka, K. Matsuoka, K. Kinoshita, Y. Miyamoto and H. Murata, "Effect of Forging Ratio and Grain Size on Tensile and Fatigue Strength of Pure Titanium Forgings", Journal of the Society of Materials Science, Japan, vol. 54, 1 (2005) 66-72 (In Japanese).

25. M. E. Kassner and X. Li, "The Effect of Grain Size on The Elevated Temperature Yield Strength of Polycrystalline Aluminum", Scripta Metallurgica et Materialia, 25 (1991) 2833-2838.

26. C. Ouchi, H. Iizumi and S. Mitao, "Effects of Ultra-High Purification and Addition of Interstitial Elements on Properties of Pure Titanium and Titanium Alloy" Materials Science and Engineering A, 243 (1998) 186-195.

27. T. Threrujirapapong, T. Mimoto, K. Kondoh, J. Umeda and B. Fugetsu, "Effects of SPS Parameters on The Mechanical Properties and Microstructures of Titanium Reinforced with Multi-wall Carbon Nanotubes Produced by Hot Extrusion", TMS 2011 140th Annual Meeting \& Exhibition, Supplemental Proceedings, vol. 2, (2011) 821-828, 27 February-3 March 2011, San Diego, California USA.

28. Y. H. Liang, H. Y. Wang, Y. F. Yang, Y. Y. Wang and Q. C. Jiang, "Evolution Process of The Synthesis of TiC in The Cu-Ti-C System", Journal of Alloys and Compounds, 452 (2008) 298-303.

29. W. F. Hosford, Mechanical Behavior of Materials, Cambridge University Press, UK (2005).

30. Y. Estrin, G. Gottstein, L. S. Shviddlerman, "Diffusion Controlled Creep in Nanocrystalline Materials under Grain Growth", Scripta Materialia, 50 (2004) 993-997.

31. M. J. R. Barboza, E. A. C. Perez, M. M. Medeiros, D. A. P. Reis, M. C. A. Nono, F. Piorino Neto and C. R. M. Silva, "Creep Behavior of Ti-6Al-4V and A Comparison with Titanium Matrix Composites", Materials Science and Engineering A, 428 (2006) 319-326.

32. B. Verlinde, J. Driver, I. Samajdar and R. D. Doherty, Thermo-Mechanical Processing of Metallic Materials, $1^{\text {st }}$ ed., Pergamon, Netherlands (2007). 


\section{List of Tables}

Table 1 Chemical compositions of the pure Ti powders (wt.\%)

\begin{tabular}{|c|c|c|c|c|c|c|c|c|c|}
\hline Materials & Purity & $\mathrm{Fe}$ & $\mathrm{Cl}$ & $\mathrm{Mg}$ & $\mathrm{Si}$ & $\mathrm{N}$ & $\mathrm{C}$ & $\mathrm{O}$ & $\mathrm{Ti}$ \\
\hline Pure Ti & $>95$ & 0.03 & $<0.002$ & $<0.001$ & 0.01 & 0.02 & $<0.01$ & 0.21 & Bal. \\
\hline
\end{tabular}

Table 2 Average Ti grain size and TiC particle size before and after annealing at $473 \mathrm{~K}$ for $360 \mathrm{ks}$ and after elevated temperature tensile testing at 473-673 K.

\begin{tabular}{|c|c|c|c|c|c|c|}
\hline \multirow{2}{*}{$\begin{array}{c}\text { Size } \\
\text { measurement }\end{array}$} & \multirow{2}{*}{ Extruded Ti } & \multirow{2}{*}{$\begin{array}{l}\text { As- } \\
\text { extruded }\end{array}$} & \multirow{2}{*}{$\begin{array}{c}\text { As- } \\
\text { annealed }\end{array}$} & \multicolumn{3}{|c|}{ Tensile test temperature, $\mathrm{K}$} \\
\hline & & & & 473 & 573 & 673 \\
\hline \multirow{4}{*}{$\begin{array}{c}\text { Ti grain size, } \\
\mu \mathrm{m}\end{array}$} & Pure Ti & 11.7 & 44.7 & 45.2 & 45.7 & 52.0 \\
\hline & $1.0 \mathrm{wt} . \% \mathrm{CNTs}$ & 8.6 & 8.4 & 8.4 & 8.5 & 10.3 \\
\hline & 2.0wt.\% CNTs & 8.6 & 8.4 & 8.4 & 8.2 & 8.7 \\
\hline & 3.0wt.\% CNTs & 7.4 & 7.7 & 7.4 & 7.7 & 7.7 \\
\hline \multirow{3}{*}{$\begin{array}{l}\text { TiC particle } \\
\text { size, } \mu \mathrm{m}\end{array}$} & $1.0 \mathrm{wt} . \% \mathrm{CNTs}$ & 2.0 & 2.1 & 2.2 & 2.2 & 2.1 \\
\hline & 2.0wt.\%CNTs & 2.0 & 1.9 & 2.1 & 2.0 & 2.0 \\
\hline & 3.0wt.\%CNTs & 2.1 & 2.0 & 2.1 & 1.9 & 2.1 \\
\hline
\end{tabular}

Table 3 Lattice parameters of Ti matrix, TiC dispersoid amount, dissolved carbon atom in Ti matrix and the carbon content analysis of the extruded Ti/CNTs composites after annealing at $473 \mathrm{~K}$ for $3.6 \mathrm{ks}$.

\begin{tabular}{|c|c|c|c|c|c|}
\hline \multirow{2}{*}{$\begin{array}{c}\text { Extruded } \\
\text { materials }\end{array}$} & \multicolumn{2}{|c|}{ Lattice parameters, $\AA$} & $\begin{array}{c}\text { TiC content, } \\
\text { wt.\% }\end{array}$ & $\begin{array}{c}\text { Dissolved carbon } \\
\text { atom, wt.\% }\end{array}$ & $\begin{array}{c}\text { Carbon content } \\
\text { analysis, wt.\% }\end{array}$ \\
\cline { 2 - 6 } & a axis & c axis & - & - & 0.01 \\
\hline Pure Ti & 2.94473 & 4.67873 & - & 0.003385 & 0.27 \\
\hline 1.0wt.\%CNTs & 2.95243 & 4.69474 & 0.61 & 0.003306 & 0.37 \\
\hline 2.0wt.\%CNTs & 2.95386 & 4.69698 & 1.58 & 0.011661 & 0.76 \\
\hline 3.0wt.\%CNTs & 2.95156 & 4.69728 & 2.55 & 0.42 & \\
\hline
\end{tabular}

* The maximum equilibrium solubility of carbon in $\alpha$-Ti from is $0.4 \mathrm{wt} . \%$ [22] 
Table 4 Incremental yield stress by grain size effect, carbon solid solution and TiC second phase of extruded Ti/CNTs composites at room temperature.

\begin{tabular}{|c|c|c|c|c|}
\hline \multirow{2}{*}{$\begin{array}{c}\text { Extruded } \\
\text { materials }\end{array}$} & \multirow{2}{*}{$\begin{array}{c}\text { Experimental } \\
\text { yield stress, MPa }\end{array}$} & \multicolumn{3}{|c|}{ Incremental yield stress, MPa } \\
\cline { 3 - 5 } & Grain size & $\begin{array}{c}\text { Carbon solid } \\
\text { solution }\end{array}$ & $\begin{array}{c}\text { Second phases } \\
\text { (TiC + CNTs) }\end{array}$ \\
\hline 1.0wt.\%CNTs & 625 & 369 & 37 & 219 \\
\hline 2.0wt.\%CNTs & 662 & 369 & 37 & 256 \\
\hline $3.0 \mathrm{wt} \% \mathrm{CNTs}$ & 853 & 378 & 54 & 421 \\
\hline
\end{tabular}




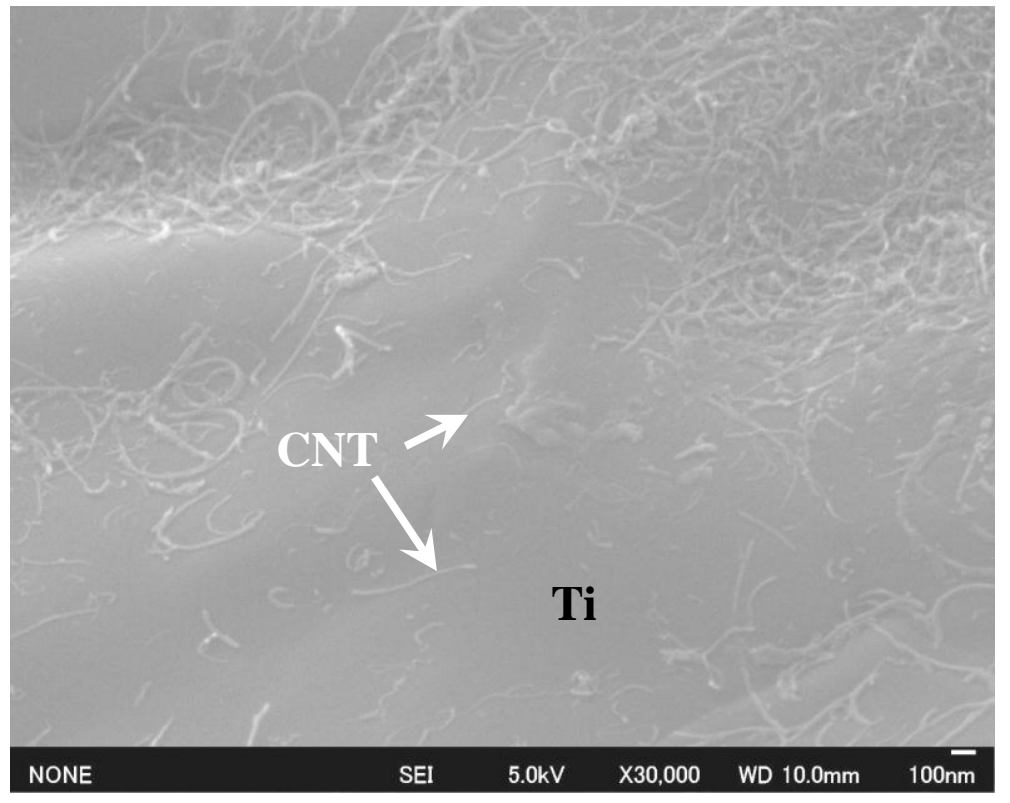

Fig. 1 High distribution of individual CNT on the Ti particle surface using $1.0 \mathrm{wt} . \% \mathrm{CNTs} /$ zwitterionic solution 

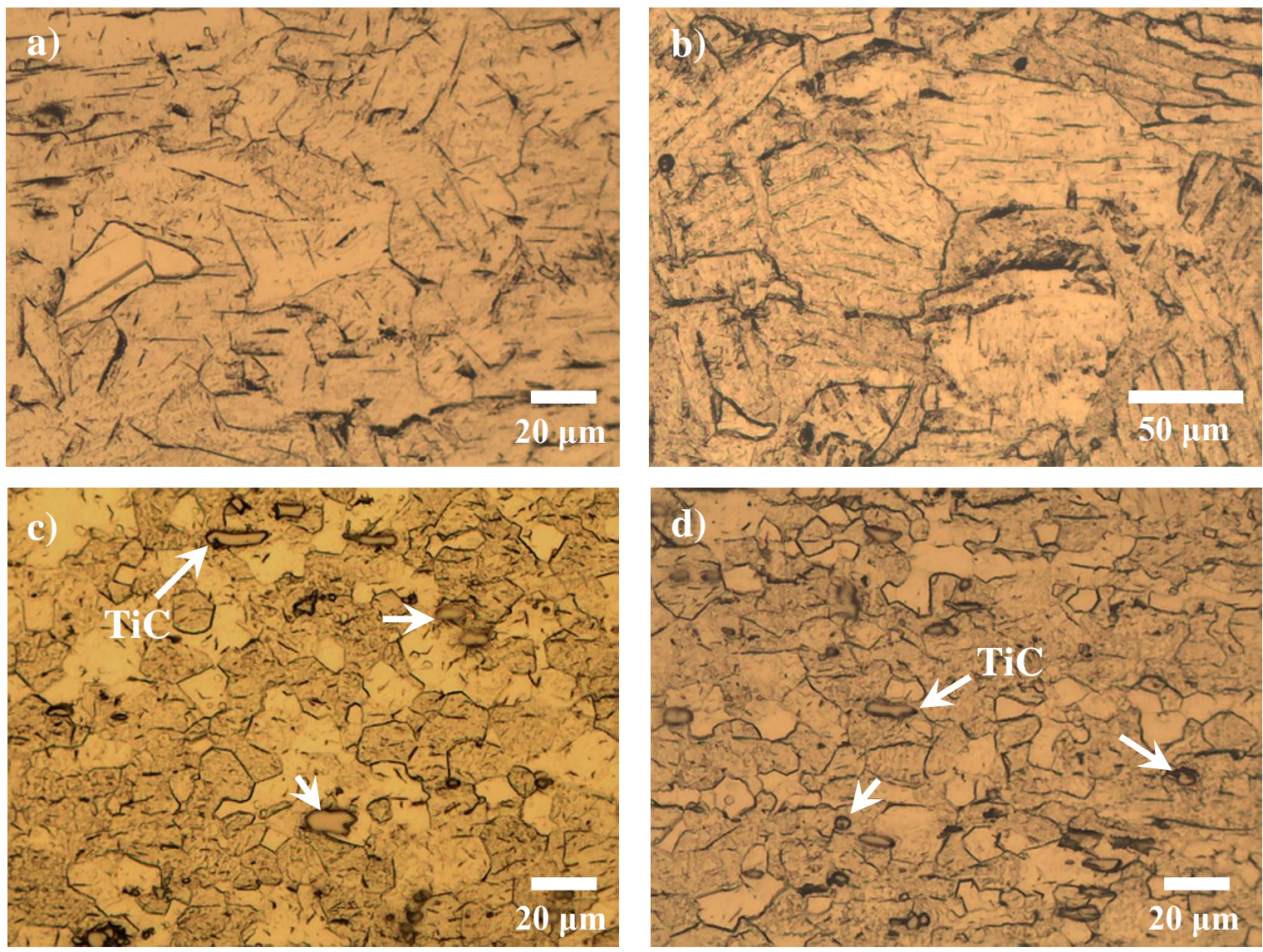

Extrusion direction

Fig. 2 Optical microstructures of the extruded pure $\mathrm{Ti}$ material without CNTs reinforcement (a) before and (b) after annealing at $473 \mathrm{~K}$ for $360 \mathrm{ks}$, compared to microstructure of the extruded pure Ti/CNT composite coated by $1.0 \mathrm{wt}$.\%CNTs/ zwitterionic solution (c) before and (d) after annealing at $473 \mathrm{~K}$ for $360 \mathrm{ks}$. 


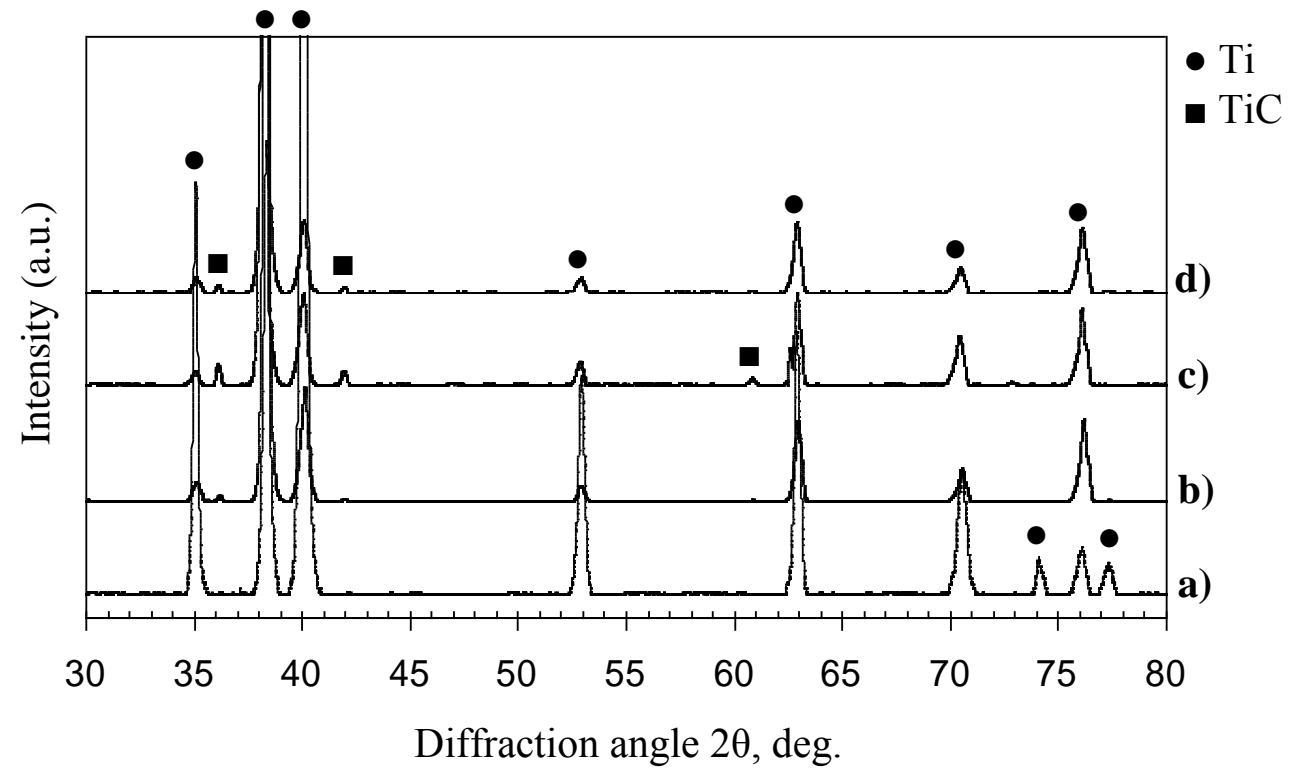

Fig. 3 XRD patterns of the extruded pure Ti composites after annealing at $473 \mathrm{~K}$, (a) without reinforcement, (b) coated by 1.0, (c) 2.0 and (d) $3.0 \mathrm{wt} \%$ CNTs/zwitterionic solution. 

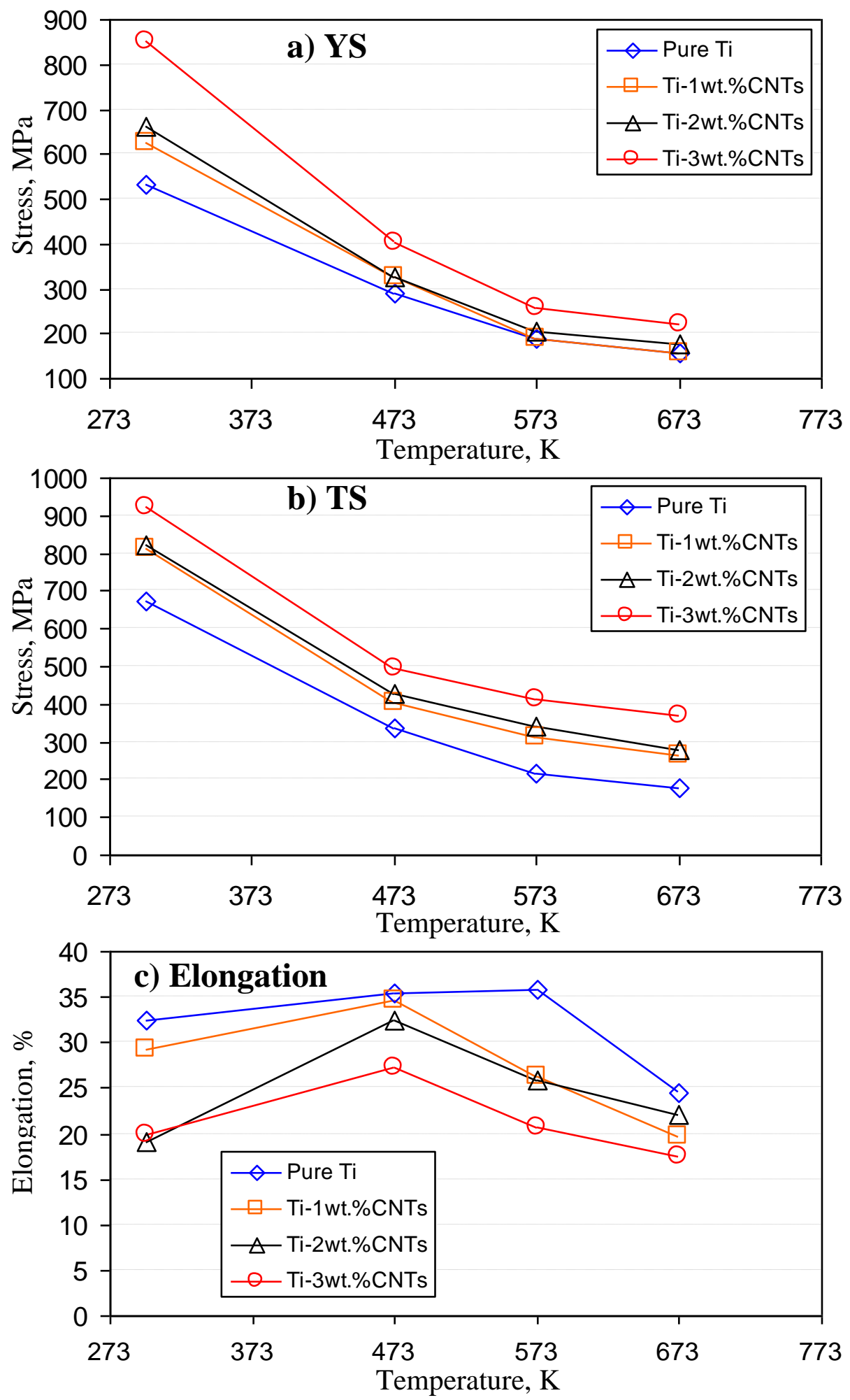

Fig. 4 Dependence of tensile properties on elevated temperatures of the extruded pure Ti composites coated by 1.0, 2.0 and 3.0 wt.\% MWCNTs/zwitterionic solution; (a) yield stress, (b) tensile strength and (c) elongation. 

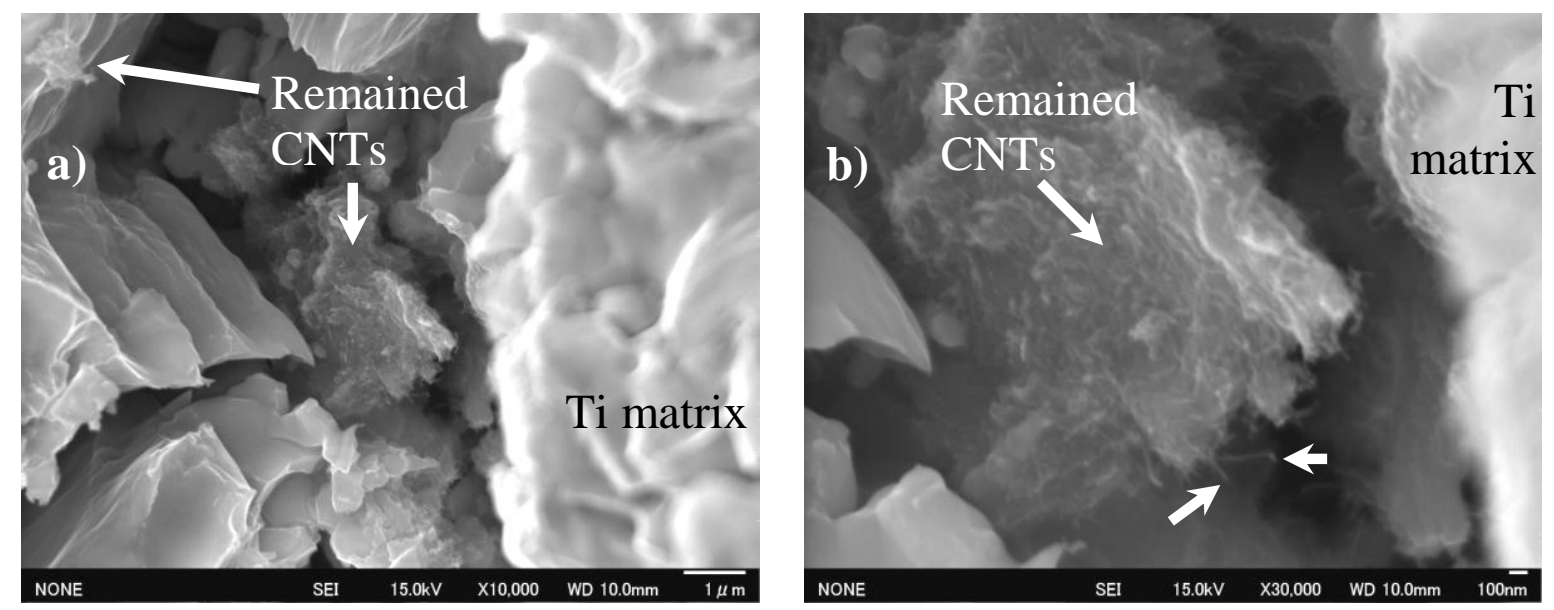

Fig. 5 SEM observation on fractured surface of the annealed sample of extruded pure Ti/CNTs coated by $1.0 \mathrm{wt} . \% \mathrm{CNTs} / \mathrm{zwitterionic}$ solution after tensile testing at $673 \mathrm{~K}$; (a) low magnification image, (b) high magnification image. 

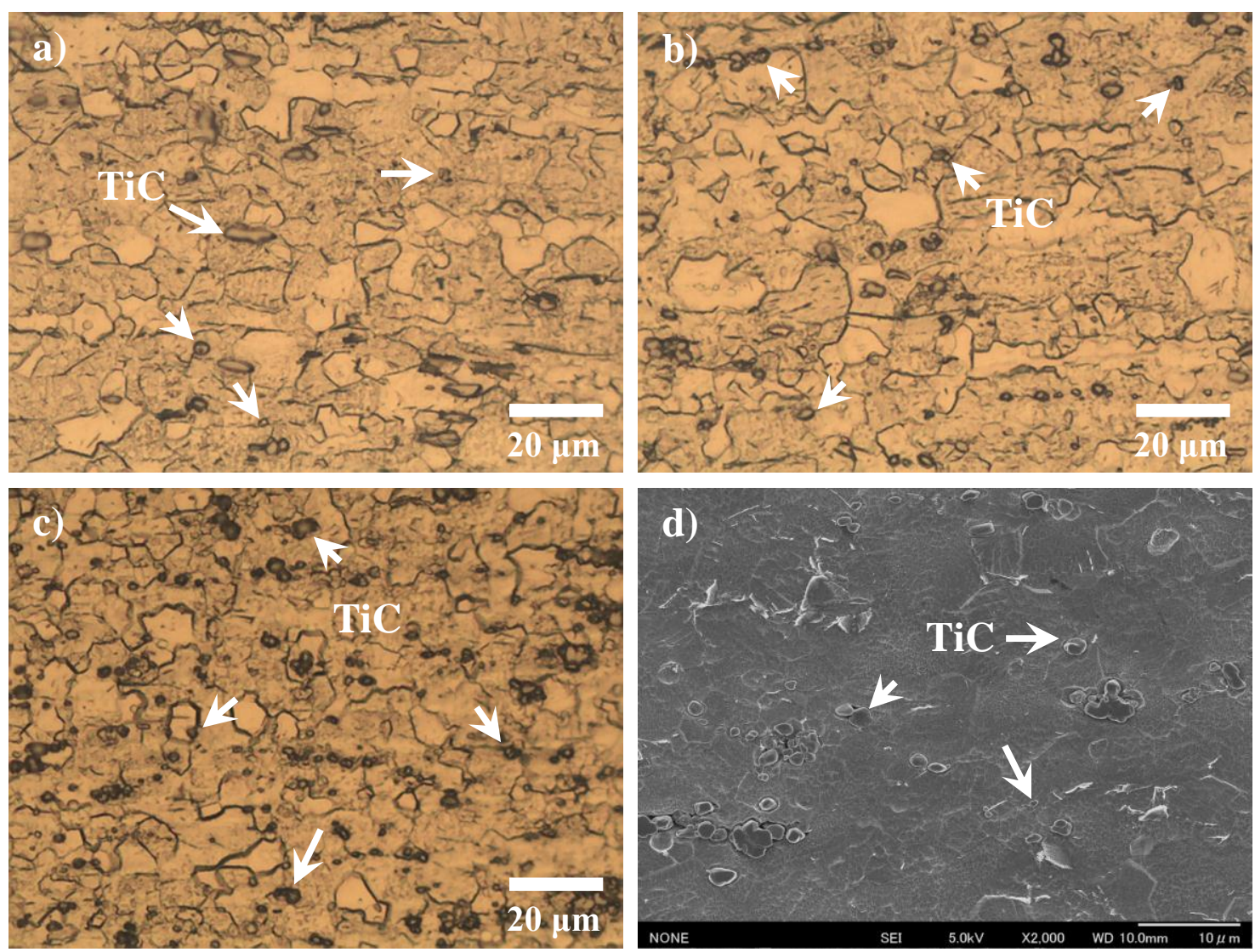

Extrusion direction

Fig. 6 Optical microstructures of the extruded pure Ti coated with (a) 1.0, (b) 2.0 and (c) 3.0 wt.\% CNT/zwitterionic solutions after annealing at $473 \mathrm{~K}$ for $360 \mathrm{ks}$ and (d) SEM microstructure at necking area of sample (c) after tensile testing at $673 \mathrm{~K}$ 


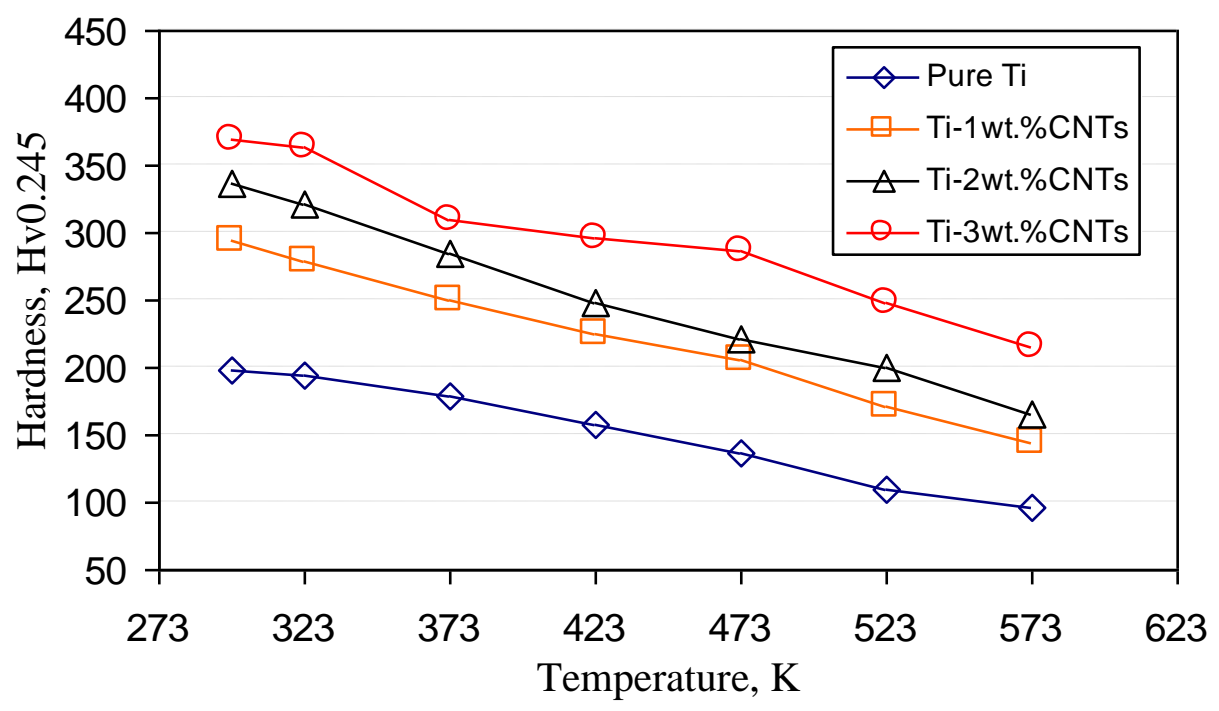

Fig. 7 Dependence of hardness on elevated temperatures of extruded pure Ti composites coated by 1.0, 2.0 and 3.0 wt.\% CNTs/zwitterionic solution. 


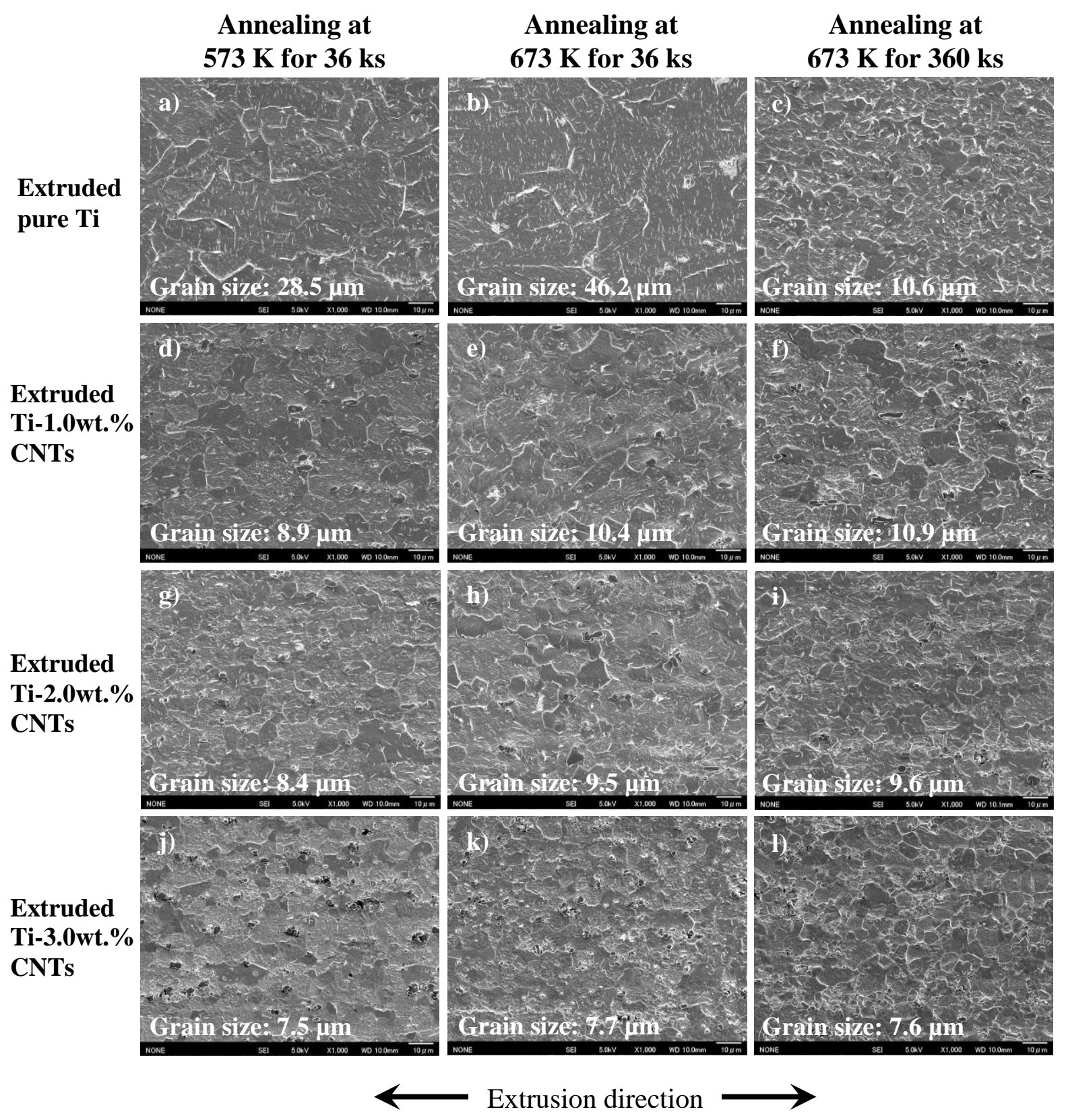

Fig. 8 Microstructure of extruded Ti/CNTs composites after annealing at 573 and $673 \mathrm{~K}$ for $36 \mathrm{ks}$ and $673 \mathrm{~K}$ for $360 \mathrm{ks}$. 


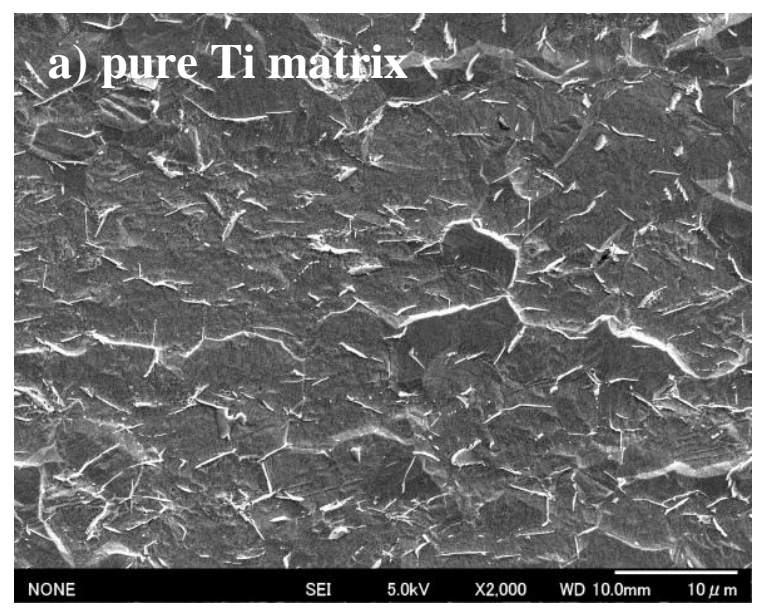

Grain size: $10.6 \mu \mathrm{m}$

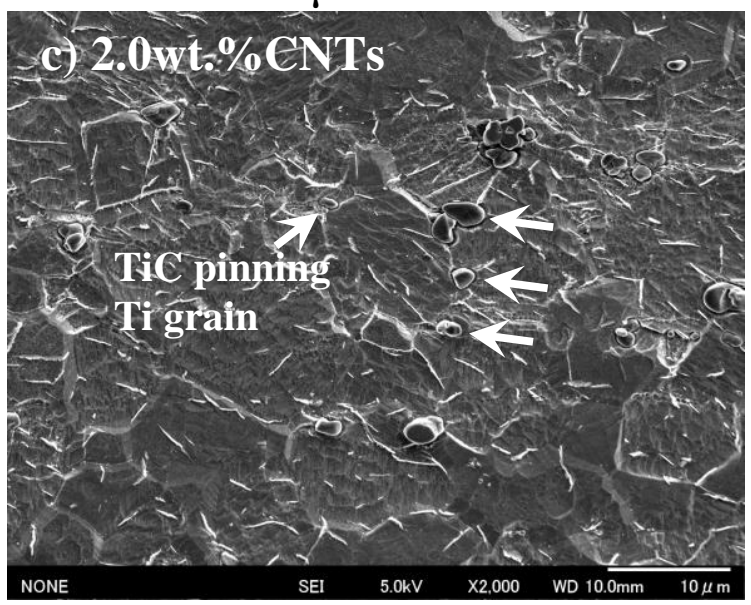

Grain size: $9.6 \mu \mathrm{m}$

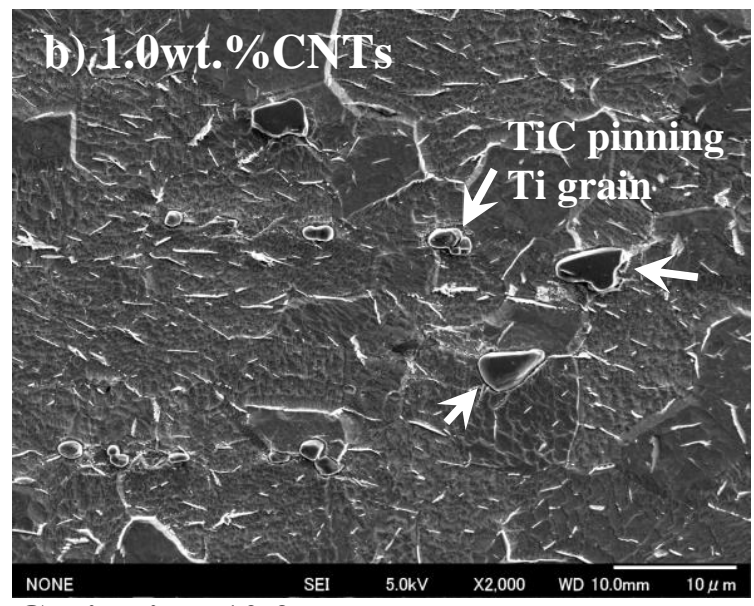

Grain size: $10.9 \mu \mathrm{m}$

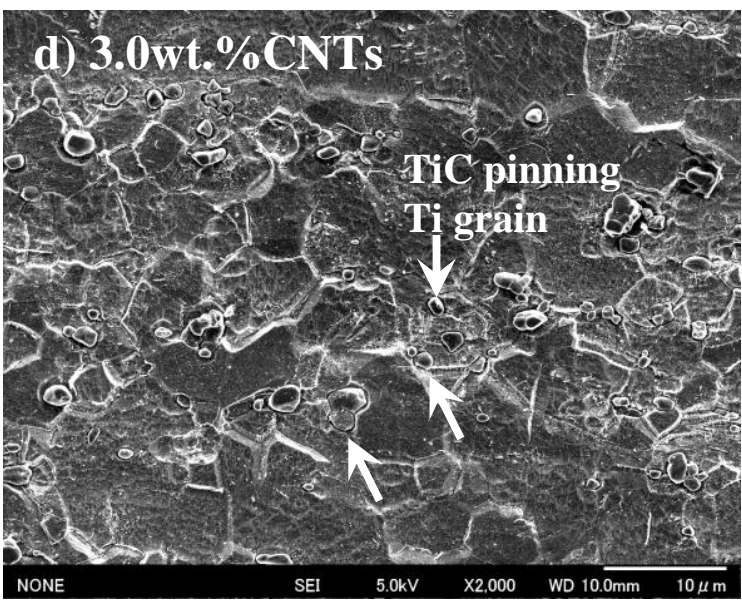

Grain size: $7.6 \mu \mathrm{m}$

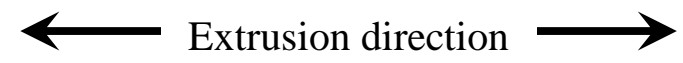

Fig. 9 SEM images of (a) recrystallized grain of extruded pure Ti material and unchanged Ti grain size due to TiC pinning effect of the samples coated by (b) $1.0 \mathrm{wt} . \%$, (c) $2.0 \mathrm{wt} . \%$ and (d) $3.0 \mathrm{wt} . \% \mathrm{CNTs} / \mathrm{zwitterionic}$ solution after annealing at $673 \mathrm{~K}$ for $360 \mathrm{ks}$. 